\title{
Histoplasmosis in HIV-positive patients in Ceará, Brazil: clinical-laboratory aspects and in vitro antifungal susceptibility of Histoplasma capsulatum isolates
}

\author{
Raimunda S.N. Brilhante ${ }^{\mathrm{a}, \mathrm{b}, \mathrm{c}, *}$, Maria A.B. Fechine ${ }^{\mathrm{a}, \mathrm{c}}$, Jacó R.L. Mesquita ${ }^{\mathrm{f}}$, \\ Rossana A. Cordeiro ${ }^{\mathrm{a}, \mathrm{b}, \mathrm{c}}$, Marcos F.G. Rocha ${ }^{\mathrm{a}, \mathrm{b}, \mathrm{d}}$, André J. Monteiro ${ }^{\mathrm{c}, \mathrm{e}}$, \\ Rita A.C. Lima ${ }^{\mathrm{a}, \mathrm{b}}$, Érica P. Caetano ${ }^{\mathrm{a}, \mathrm{b}}$, Juliana F. Pereira ${ }^{\mathrm{a}, \mathrm{b}}$, \\ Débora S.C.M. Castelo-Branco ${ }^{\mathrm{a}, \mathrm{b}}$, Zoilo P. Camargo ${ }^{\mathrm{g}}$, José J.C. Sidrim ${ }^{\mathrm{a}, \mathrm{b}, \mathrm{c}}$
}

a Specialized Medical Mycology Center, Federal University of Ceará, Fortaleza, Ceará, Brazil

b Postgraduate Program in Medical Microbiology, Federal University of Ceará, Fortaleza, Ceará, Brazil

c Postgraduate Program in Medical Sciences, Federal University of Ceará, Fortaleza, Ceará, Brazil

d Postgraduate Program in Veterinary Science, State University of Ceará, Fortaleza, Ceará, Brazil

e Department of Statistics and Applied Mathematics, Federal University of Ceará, Fortaleza-CE, Brazil

${ }^{\mathrm{f}}$ Hospital São José, Ceará, Brazil

g Federal University of São Paulo, São Paulo, São Paulo, Brazil

\section{A R T I C L E I N F O}

\section{Article history:}

Received 30 June 2011

Received in revised form 15 May 2012

Accepted 15 May 2012

Available online 14 June 2012

\section{Keywords:}

Brazil

AIDS

Histoplasmosis

Antifungal susceptibility

Histoplasma capsulatum

Epidemiology

\begin{abstract}
A B S T R A C T
This study contains a descriptive analysis of histoplasmosis in AIDS patients between 2006 and 2010 in the state of Ceará, Brazil. Additionally, the in vitro susceptibility of Histoplasma capsulatum isolates obtained during this period was assessed. We report 208 cases of patients with histoplasmosis and AIDS, describing the epidemiological, clinical, laboratory and therapeutic aspects. The in vitro antifungal susceptibility test was carried out by the microdilution method, according to Clinical and Laboratory Standards Institute, with $H$. capsulatum in the filamentous and yeast phases, against the antifungals amphotericin $\mathrm{B}$, fluconazole, itraconazole, voriconazole and caspofungin. In $38.9 \%$ of the cases, histoplasmosis was the first indicator of AIDS and in $85.8 \%$ of the patients the CD4 cell count was lower than 100 cells $/ \mathrm{mm}^{3}$. The lactate dehydrogenase levels were high in all the patients evaluated, with impairment of hepatic and renal function and evolution to death in $42.3 \%$ of the cases. The in vitro susceptibility profile demonstrated there was no antifungal resistance among the isolates evaluated. There was a significant increase in the number of histoplasmosis cases in HIV-positive patients during the period surveyed in the state of Ceará, northeastern Brazil, but no antifungal resistance among the recovered isolates of $H$. capsulatum. (C) 2012 Royal Society of Tropical Medicine and Hygiene. Published by Elsevier Ltd.
\end{abstract} All rights reserved.
* Corresponding author. Present address: Rua Barão de Canindé, 210; Montese. CEP: 60.425-540. Fortaleza, CE, Brazil. Fax: +55 8532951736 .

E-mail address: brilhante@ufc.br (R.S.N. Brilhante).

\section{Introduction}

Histoplasmosis is the most prevalent systemic mycosis in the Americas. Its etiological agent is the dimorphic fungus Histoplasma capsulatum, which is widely distributed throughout the world. ${ }^{1}$

Since the 1980s, extrapulmonary histoplasmosis has been considered an important marker disease of AIDS 
occurring in up to $5 \%$ of patients infected with HIV in endemic areas. ${ }^{2}$ It is the most frequent opportunistic systemic infection found in this group, ${ }^{3}$ with high mortality rates, and is often confused with other diseases such as tuberculosis and pneumocystosis. ${ }^{4}$

The treatment of histoplasmosis depends on the severity of the infection, clinical manifestations and individual risk factors. The drugs used to treat patients are amphotericin B, fluconazole, itraconazole, voriconazole, posaconazole or caspofungin. ${ }^{5}$

Various outbreaks of histoplasmosis have been reported in the Americas, such as in the city of Indianapolis, United States, where 155 cases were reported between 1988 and 1995 (average of 22.14 cases a year), ${ }^{2}$ and in French Guiana, with 200 cases from 1982 to 2007 (yearly average of 8 cases). ${ }^{3}$ In Brazil, outbreaks of histoplasmosis have been described in several regions, ${ }^{6-8}$ with up to 10 cases a year. Specifically in the northeast region, Daher et al. ${ }^{9}$ reported 164 cases of disseminated histoplasmosis in HIV-positive patients in the state of Ceará from January 1995 to January 2004 (average of 18 cases a year).

This article contains a descriptive analysis of the histoplasmosis cases in HIV-positive patients from 2006 to 2010 in the state of Ceará, northeastern Brazil. We also report in vitro susceptibility tests of the isolates of $H$. capsulatum recovered from these cases against the most commonly used antifungals.

\section{Materials and methods}

A survey was conducted of cases of histoplasmosis and AIDS, diagnosed in a tertiary reference hospital for infectious diseases in the state of Ceará, between January 2006 and December 2010. The study protocol was reviewed and approved by the hospital's ethics committee, under number 029/2007.

The diagnosis of histoplasmosis was confirmed by identification of $H$. capsulatum through mycological examination of samples obtained from peripheral blood smear, bone marrow aspirate, blood and bone marrow culture, and histopathology of different tissues, ${ }^{10}$ while HIV infection was confirmed according to the criteria of CDC. ${ }^{11}$

We gathered information on demographics (sex, age and place of residence), clinical aspects (date of histoplasmosis diagnosis, period of hospitalization, symptoms, signals, treatment and evolution of the patient), mycological diagnosis (direct examinations and fungal culture) and other laboratory data (complete hemogram, serum creatinine and hepatic function tests, CD4 cell count and chest $\mathrm{x}$-ray).

To measure the antifungal susceptibility in vitro, the microdilution method was used, according to protocol M27-A2, ${ }^{11,12}$ with 68 clinical isolates of $H$. capsulatum var. capsulatum (H. capsulatum) in filamentous form, obtained from patients surveyed in this study and stored in the collection of the Specialized Medical Mycology Center of Ceará Federal University, as well as with eight isolates chosen at random in yeast form. The assays were conducted in a Level 3 biosecurity laboratory.

The fungal inocula were prepared according to earlier reports. ${ }^{11,13}$ The final concentrations were obtained by serial dilutions, with intervals varying from $0.002-1.0$, $0.98-500,0.0001-0.06,0.002-1.0$ and $0.016-64 \mu \mathrm{g} \mathrm{ml}^{-1}$ for amphotericin $\mathrm{B}$, fluconazole, itraconazole, voriconazole and caspofungin, respectively. The strain of Candida parapsilosis ATCC 22019, as recommended by the Clinical and Laboratory Standards Institute, ${ }^{12}$ were used as controls. The MICs of the drugs were read as described in the protocol. $^{12}$

The data were subjected to Student's t-test for variables with approximately normal distribution, the Mann-Whitney test for variables with the presence of extreme values, and the $\chi^{2}$ test for comparison between the categorical variables and for independence analysis.

\section{Results}

There were a total of 208 cases of patients with histoplasmosis and AIDS from January 2006 to December 2010. Of these, $81.7 \%$ (170/208) of the individuals were men and $18.3 \%(38 / 208)$ were women, a ratio of $4.5: 1$, with average ages of 35.8 and 35.0 years, respectively.

In $38.9 \%(81 / 208)$ of the cases, histoplasmosis was the first indicator of AIDS, and at the moment of histoplasmosis diagnosis, $80.3 \%(167 / 208)$ of the patients were not being treated with highly active antiretroviral therapy (HAART). The clinical aspects of the patients are shown in Table 1.

In $51.4 \%$ (107/208) of the cases there was a positive reaction in the direct examinations, while $H$. capsulatum was isolated in $92.3 \%$ (192/208) of the clinical sample cultures. The CD4 count was performed on blood samples from 120 patients. As can be seen in Table 2, 85.8\% (103/120) of these had CD4 counts less than or equal to 100 cells $/ \mathrm{mm}^{3}$. The hemoglobin levels were lower than $8 \mathrm{~g} / \mathrm{dl}$ in 43.3\% (90/208)

\section{Table 1}

Clinical manifestations of histoplasmosis in patients with AIDS in Ceará, between January 2006 and December 2010

\begin{tabular}{lc}
\hline Clinical Aspects & $\mathrm{n}(\%)$ \\
\hline General symptoms $(\mathrm{n}=208)$ & $195(93.8)$ \\
Fever & $181(87.0)$ \\
Weight loss & $150(72.1)$ \\
Anorexia & $117(56.3)$ \\
Adynamia & $39(18.8)$ \\
Headache & $32(15.4)$ \\
Lymphadenopathy & \\
Pulmonary symptoms $(\mathrm{n}=208)$ & $158(76.0)$ \\
Cough & $104(50.0)$ \\
Dyspnea & $16(7.7)$ \\
Chest pain & \\
X-ray examination $(\mathrm{n}=185)$ & $123(66.5)$ \\
Interstitial infiltrate & $23(12.4)$ \\
Pleural effusion & $4(2.2)$ \\
Reticulonodular infiltrate & $4(2.2)$ \\
Mixed infiltrate & $1(0.5)$ \\
Alveolar infiltrate & $1(0.5)$ \\
Fibrocavitary disease & \\
Digestive symptoms $(\mathrm{n}=208)$ & $111(53.4)$ \\
Diarrhea & $49(23.6)$ \\
Vomiting & $126(60.6)$ \\
Hepatomegaly $(\mathrm{n}=208)$ & $102(49.0)$ \\
Splenomegaly $(\mathrm{n}=208)$ & $15(41.6)$ \\
Cutaneous lesions $(\mathrm{n}=36)$ & $12(33.4)$ \\
Erythema & $9(25.0)$ \\
Papula & \\
Erythema + papula & \\
\hline
\end{tabular}


Table 2

Laboratory tests of patients with histoplasmosis and AIDS in Ceará, between January 2006 and December 2010

\begin{tabular}{|c|c|c|c|c|}
\hline Hematological results & $\mathrm{n}$ & Mean & $\mathrm{n}(\%)$ & Variation \\
\hline CD4 cell count, cells $/ \mathrm{mm}^{3}$ & 120 & $53 \pm 55.1$ & & $2-303$ \\
\hline $1-50$ & & & $75(62.5)$ & \\
\hline $51-100$ & & & $28(23.3)$ & \\
\hline $101-200$ & & & $14(11.7)$ & \\
\hline$>200$ & & & $3(2.5)$ & \\
\hline Hemoglobin, g/dl & 208 & $8.56 \pm 2.03$ & & $3.7-15.2$ \\
\hline$\leq 8.0$ & & & $90(43.3)$ & \\
\hline $8.0-11.5$ & & & $105(50.4)$ & \\
\hline$>11.5$ & & & $13(6.3)$ & \\
\hline Leukocytes, cells $/ \mathrm{mm}^{3}$ & 208 & $4297 \pm 3822$ & & $500-32000$ \\
\hline$<3500$ & & & $111(53.4)$ & \\
\hline$\geq 3500$ & & & $97(46.6)$ & \\
\hline Platelet count, cells $/ \mathrm{mm}^{3}$ & 208 & $117228 \pm 100041$ & & $117-642000$ \\
\hline$<100000$ & & & $108(51.9)$ & \\
\hline $100000-150000$ & & & $44(21.2)$ & \\
\hline$\geq 150000$ & & & $56(26.9)$ & \\
\hline AST, IU $/ 1^{\mathrm{a}}$ & 205 & $174 \pm 167$ & & $8-856$ \\
\hline$\leq 34$ & & & 40 (19.5) & \\
\hline$\geq 35$ & & & $165(80.5)$ & \\
\hline ALT, IU $/ \mathrm{l}^{\mathrm{b}}$ & 203 & $64.9 \pm 63.0$ & & 4-493 \\
\hline$\leq 44$ & & & $67(33.0)$ & \\
\hline$\geq 45$ & & & $136(67.0)$ & \\
\hline $\mathrm{LDH}, \mathrm{IU} / \mathrm{I}^{\mathrm{c}}$ & 205 & $3852 \pm 3576$ & & $164-14868$ \\
\hline Increase $<2 x$ & & & $19(9.3)$ & \\
\hline Increase $\geq 2 \mathrm{x}$ & & & $186(90.7)$ & \\
\hline Creatinine, $\mathrm{mg} / \mathrm{dl}^{\mathrm{d}}$ & 205 & $1.5 \pm 2.03$ & & $0.3-12.8$ \\
\hline$\leq 0.7$ & & & $60(29.3)$ & \\
\hline $0.8-1.3$ & & & $94(45.8)$ & \\
\hline$\geq 1.4$ & & & $51(24,9)$ & \\
\hline
\end{tabular}

a Aspartate aminotransferase, normal values 15 a $37 \mathrm{U} / 1$.

${ }^{\mathrm{b}}$ Alanine aminotransferase, normal values 30 a $65 \mathrm{U} / 1$.

c Lactate dehydrogenase, normal values $\leq 225 \mathrm{UI} / \mathrm{l}$.

${ }^{\mathrm{d}}$ Creatinine normal values $\leq 1.3 \mathrm{U} / \mathrm{l}$.

of the cases, while the leukocyte levels were lower than 3500 in $53.4 \%(111 / 208)$ and the platelet counts smaller than 100000 cells $/ \mathrm{mm}^{3}$ in $51.9 \%(108 / 208)$ of the individuals. The lactate dehydrogenase (LDH) levels were elevated in all the patients assessed, with an average of $3852 \pm 3576$ $\mathrm{U} / \mathrm{l}$ (164-14868 U/1). There was impaired hepatic function, demonstrated by high levels of aspartate aminotransferase (AST), in 165 (80.5\%) of the 208 patients evaluated, with an average result four times higher than the normal levels, while $67.0 \%(136 / 208)$ of the patients had high levels of alanine aminotransferase (ALT). Finally, impaired renal function was observed in $24.9 \%(51 / 208)$ of the cases, with serum creatinine higher than $1.4 \mathrm{U} / \mathrm{L}$.

The antifungal chosen to treat $86.5 \%(180 / 208)$ of the patients was amphotericin B, and of these $38.3 \%$ (69/180) died. No therapy was given in $13.5 \%$ (28/208) of the cases and the mortality rate of these patients was $67.9 \%$ (19/28).
According to the in vitro susceptibility tests, the $H$. capsulatum isolates in the filamentous phase $(n=68)$ presented variation of MICs of $0.0078-0.5$; 3.9-125; $0.001-0.0312 ; 0.0078-0.5 ; 0.016-32 \mu \mathrm{g} / \mathrm{mL}$, for amphotericin $\mathrm{B}$, fluconazole, itraconazole, voriconazole and caspofungin, respectively. For the $H$. capsulatum isolates in the yeast phase $(n=8)$, the following MIC results were observed: $0.06-0.5 ; 3.9-7.8 ; 0.0039-0.03 ; 0.002-0.03$; 1.0-4.0 $\mu \mathrm{g} \mathrm{ml}^{-1}$, for amphotericin $\mathrm{B}$, fluconazole, itraconazole, voriconazole and caspofungin, respectively (Table 3 ).

\section{Discussion}

$H$. capsulatum can be considered one of the most important opportunistic pathogens at present, mainly because of the relationship with AIDS. It causes serious disseminated infections which are often fatal, particularly in patients

Table 3

Antifungal MIC range against the isolates of Histoplasma capsulatum

\begin{tabular}{|c|c|c|c|c|}
\hline \multirow[t]{3}{*}{ Antifungals } & \multicolumn{4}{|l|}{$\operatorname{MIC}(\mu \mathrm{g} / \mathrm{mL})$} \\
\hline & \multicolumn{2}{|c|}{ Filamentous form $(\mathrm{n}=68)$} & \multicolumn{2}{|c|}{ Yeast form $(n=8)$} \\
\hline & Range & Mean & Range & Mean \\
\hline Amphotericin B & $0.0078-0.5$ & 0.12 & $0.06-0.5$ & 0.16 \\
\hline Fluconazole & $3.9-125$ & 36.36 & $3.9-7.8$ & 5.52 \\
\hline Itraconazole & $0.001-0.0312$ & 0.0073 & $0.0039-0.03$ & 0.016 \\
\hline Voriconazole & $0.0078-0.5$ & 0.097 & $0.002-0.03$ & 0.010 \\
\hline Caspofungin & $0.016-32$ & 3.65 & $1-4$ & 2.0 \\
\hline
\end{tabular}


with CD4 counts lower than 150 cells $/ \mathrm{mm}^{3}$, in the absence of HAART. ${ }^{14}$

In the beginning of the twenty-first century an increase has been noted in the number of histoplasmosis cases, as can be observed in this study: there were 208 cases between 2006 and 2010, vs 164 cases during nine years (1995-2004) in a previous study at the same hospital. ${ }^{9}$ These numbers are also higher than those reported in microepidemics in southeastern and southern Brazil, as well as in other South American countries. 8,15

According to data from the Brazilian Ministry of Health ${ }^{16}$ the number of HIV-positive patients in southeastern Brazil is higher than that of the northeastern region. Thus, it was expected that the number of cases of histoplasmosis in HIV-positive patients would follow this tendency. However, in the present study and in the study of Daher et al., ${ }^{17}$ the number of cases of histoplasmosis in the state of Ceará was greater than those from southeastern states of Brazil. 6,8

Histoplasmosis is the first opportunistic infection in $22-85 \%$ of HIV-positive patients in endemic areas ${ }^{3}$ and the state of Ceará is endemic for the disease, as shown by the serological investigation with histoplasmin carried out in the city of Pereiro, Ceará, in individuals of both sexes and age range from 5-50 years. The positive frequency was $61.5 \%$, higher than observed in other Brazilian states, including the northeastern region. ${ }^{15}$

Histoplasmosis was observed as the first manifestation of AIDS in $38.9 \%$ of the cases, and $85.8 \%$ of the patients presented CD 4 counts $<100$ cells $/ \mathrm{mm}^{3}$, corroborating earlier studies that showed cell immunosuppression to be the most important factor for clinical manifestations of histoplasmosis. ${ }^{3}$

The epidemiological, clinical, laboratory and radiological characteristics of the patients found in the present study are similar to those reported elsewhere in the literature. ${ }^{17}$ It should be noted that cutaneous alterations were less frequently observed (17.3\%) than in southern and southeastern Brazil, but at similar levels as reported in the midwest region of Brazil and in the United States. ${ }^{7,18}$ In the present study gastrointestinal symptoms (diarrhea and vomiting) occurred more often than in the American study $^{18}$ and with greater hepatosplenic impairment than previously observed in Ceará, ${ }^{17}$ suggesting that different $H$. capsulatum isolates are responsible for different clinical manifestations. ${ }^{19}$ Additionally, the presence of certain clinical signs were associated with worse prognosis and death, such as anorexia, dyspnea, elevated serum levels of AST and creatinine, diffuse interstitial pulmonary infiltrate and pleural effusion.

A total of $42.3 \%(88 / 208)$ of the patients died, out of which $78.4 \%(69 / 88)$ were being treated with amphotericin B and the remaining 21.6\% (19/88) were not under antifungal therapy. This lethality rate was higher than that observed by Daher et al. ${ }^{17}$ (32\% of 164 patients), but similar to that observed by Chang et al. ${ }^{7}$ (40\%). Additionally, Wheat et al. ${ }^{2}$ reported that $12 \%$ of AIDS patients with disseminated histoplasmosis treated with amphotericin $\mathrm{B}$ died, with a lethality rate lower than the one observed in this study. These data show that histoplasmosis is a serious opportunistic infection with high lethality rates among immunocompromised patients. ${ }^{18}$

According to the results of the in vitro tests, the MICs of amphotericin B vs the H. capsulatum isolates, in the filamentous phase, were lower than those observed by Andreu et al., ${ }^{20}$ who found an MIC of $0.125-1.0 \mu \mathrm{g} \mathrm{ml}^{-1}$, and by $\mathrm{Li}$ et al., ${ }^{21}$ who reported an $\mathrm{MIC}_{90}$ of $1 \mu \mathrm{g} \mathrm{ml}{ }^{-1}$. Polak and Dixon, ${ }^{22}$ in a study of the yeast phase, obtained MIC values of $0.07-0.15 \mu \mathrm{g} / \mathrm{ml}$, similar to those observed in the present study.

In relation to the azoles, the geometric mean for fluconazole observed in this study was lower than that noted by Andreu et al. ${ }^{20}(55.7 \mu \mathrm{g} / \mathrm{ml})$, utilizing the fungus in the filamentous phase. For the yeast phase, we obtained higher MIC values for fluconazole than those reported by Polak and $\operatorname{Dixon}^{22}(0.25-5 \mu \mathrm{g} / \mathrm{mL})$ and Wheat et al. ${ }^{23}(0.24-4 \mu \mathrm{g} / \mathrm{mL})$ versus the yeast form of $H$. capsulatum. It should be mentioned that treatment of histoplasmosis with high doses of fluconazole induces remission in the majority of patients, but many of them suffer relapses. ${ }^{24}$ Wheat et al. ${ }^{25}$ reported the emergence of resistance to fluconazole as a cause of therapeutic failure in immunosuppressed patients, mainly when in vitro studies demonstrate that the strains need concentrations higher than $5.0 \mu \mathrm{g} \mathrm{ml}^{-1}$ for inhibition.

The MIC values observed in this study for itraconazole were lower than those reported by Andreu et al. ${ }^{20}$ $\left(\mathrm{CIM}_{90}=0.125 \mu \mathrm{g} / \mathrm{ml}\right)$, and Li et al. ${ }^{21}\left(\mathrm{CIM}_{90}=0.06 \mu \mathrm{g} / \mathrm{ml}\right)$, in the filamentous phase, and similar to those reported by Polak and Dixon ${ }^{22}$ for the yeast phase, with a geometric mean of $0.019 \mu \mathrm{g} / \mathrm{ml}$.

Voriconazole is from the triazole class. Studies have demonstrated that it is more active in vitro against dimorphic fungi, such as Blastomyces dermatitidis, Coccidioides immitis and $H$. capsulatum. ${ }^{26,27}$ We observed lower MIC values for voriconazole than those reported by Li et al. ${ }^{21}$ $(0.03-2 \mu \mathrm{g} / \mathrm{ml})$ for the fungus in the filamentous phase, but similar to those found by Wheat et al. ${ }^{23}(0.007-0.25 \mu \mathrm{g} / \mathrm{ml})$ for the yeast phase.

The results obtained for caspofungin show great variability in the in vitro response of $H$. capsulatum. Kohler et al. $^{28}$ demonstrated that caspofungin is not effective against this fungus in vivo, reflecting its low activity in vitro.

Finally, this study revealed a significant increase in the number of histoplasmosis cases related to AIDS, but without noting resistance among the studied $H$. capsulatum isolates.

Authors' Contributions: RSNB, RAC, MFGR, AJM, ZPC and JJCS conceived and designed the study, analyzed the data, critically revised the manuscript for intellectual content and read and approved the final version; MABF, JRLM, RACL, EPC, JFC and DSCMCB conceived and designed the study, interpreted the data, drafted the manuscript and read and approved the final version. RSNB is the guarantor of the paper.

Funding: This work was funded by the National Council for Scientific and Technological Development (CNPq; Brazil; PROTAX Process: 562296/2010-7, CNPq processes $552161 / 2011-0$ and $304779 / 2011-3)$ and by the Brazilian 
Federal Agency for the Support and Evaluation of Graduate Education (CAPES; Brazil; PNPD Process: 2103/2009).

Competing interests: None to declare.

Ethical approval: The study protocol was reviewed and approved by the ethics committee of Hospital São José (protocol number 029/2007). Hospital São José de Doenças Infecciosas, Rua Nestor Barbosa, 315, Parquelândia, CEP: 60.455-610, Fortaleza, Ceará, Brazil. Telephone number: +55 85 3101-2321/3101-2322.

\section{References}

1. Baddley JW, Sankara IR, Rodriguez JM, Pappas PG, Many WJJ. Histoplasmosis in HIV-infected patients in a southern regional medical center: poor prognosis in the era of highly active antiretroviral therapy. Diagn Microbiol Infect Dis 2008;62:151-6.

2. Wheat LJ, Chetchotisakd P. Factors associated with severe manifestations of histoplasmosis in AIDS. Clin Infect Dis 2000;30: 877-81.

3. Huber F, Nacher M, Aznar C, et al. AIDS-related Histoplasma capsulatum var. capsulatum infection: 25 years experience of French Guiana. AIDS 2008;22:1047-53.

4. Couppie P, Sobesky M, Aznar C, et al. Histoplasmosis and acquired immunodeficiency syndrome: A study of prognostic factors. Clin Infect Dis 2004;38:134-8.

5. Wheat LJ, Freifeld AG, Kleiman MB, et al. Clinical practice guidelines for the management of patients with histoplasmosis: 2007 update by the Infectious Diseases Society of America. Clin Infect Dis 2007;45: 807-25.

6. Oliveira FM, Unis G, Severo LC. An outbreak of histoplasmosis in the city of Blumenau, Santa Catarina [in Portuguese]. J Bras Pneumol 2006;32:375-8.

7. Chang MR, Taira LC, Paniago AMM, Taira DL, Cunha RV, Wanke B. Study of 30 cases of histoplasmosis observed in the Mato Grosso do Sul State, Brazil. Rev Inst Med Trop São Paulo 2007;49:37-9.

8. Mora DJ, Santos CTB, Silva-Vergara ML. Disseminated histoplasmosis in acquired immunodeficiency syndrome patients in Uberaba, MG, Brazil. Mycoses 2007;51:136-40.

9. Daher EF, Barros FAS, Silva GBJ, et al. Risk factors for death in acquired immunodeficiency syndrome-associated disseminated histoplasmosis. Am J Trop Med Hyg 2006;74:600-3.

10. Brilhante RSN, Fechine MAB, Cordeiro RA, et al. In vitro effect of sulfamethoxazole-trimethoprim against Histoplasma capsulatum var. capsulatum. Antimicrob Agents Chemother 2010;54:3978-9.

11. Centers for Disease Control and Prevention (CDC). WHO case definitions of HIV for surveillance and revised clinical staging and immunological classification of HIV-related disease in adults and children. 2007. http://www.who.int/hiv/pub/guidelines/ HIVstaging150307.pdf [accessed 5 May 2011].
12. National Committee for Clinical Laboratory Standards. Reference method for broth dilution antifungal susceptibility testing of yeasts: approved standard. 2nd ed. NCCLS document M27-A2. Wayne, PA: NCCLS; 2002.

13. Cordeiro RA, Brilhante RSN, Rocha MFG, et al. In vitro activities of caspofungin, amphotericin $B$ and azoles against Coccidioides posadasii strains from northeast Brazil. Mycopathologia 2006;161:21-6.

14. Barnett D, Walker B, Landay A, Denny TN. CD4 immunophenotyping in HIV infection. Nat Rev Microbiol 2008;6:7-15.

15. Cermenõ JR, Cermenõ JJ, Hernandez I, et al. Histoplasmine and paracoccidiodine epidemiological study in Upata, Bolıvar state, Venezuela. Trop Med Int Health 2005;10:216-9.

16. Brazilian Ministry of Health. Epidemiological Bulletin - AIDS and STD. [in Portuguese]. Brazil: Ministério da Saúde; 2010.

17. Daher EF, Silva GBJ, Barros FA, et al. Clinical and laboratory features of disseminated histoplasmosis in HIV patients from Brazil. Trop Med Int Health 2007;12:1108-15.

18. Karimi K, Wheat J, Connoly P, et al. Differences in histoplasmosis in patients with acquired immunodeficiency syndrome in the United States and Brazil. J Infect Dis 2002;186:1655-60.

19. Durkin MM, Connolly PA, Karimi K, et al. Pathogenic differences between North American and Latin American strains of Histoplasma capsulatum var. capsulatum in experimentally infected mice. J Clin Microbiol 2004;42:4370-3.

20. Andreu CM, León AM, Medina YE, Machín GM, Lancha MR, Zaragozi MT. In vitro susceptibility of Histoplasma capsulatum to amphotericin B, ketoconazole, itraconazole and fluconazole [in Spanish]. Rev Cubana Med Trop 2003;55:76-82.

21. Li R, Ciblak MA, Nordoff N, Pasarell L, Warnock DW, McGinnis MR. In vitro activities of voriconazole, itraconazole, and amphotericin b against Blastomyces dermatitidis, Coccidioides immitis, and Histoplasma capsulatum. Antimicrob Agents Chemother 2000;44:1734-6.

22. Polak AM, Dixon DM. Fungistatic and fungicidal effects of amphotericin B, ketoconazole and fluconazole (UK 49858) against Histoplasma capsulatum var. capsulatum in vitro and in vivo. Mykosen 1987;30:186-94.

23. Wheat LJ, Connolly P, Smemeda M, et al. Activity of newer triazoles against Histoplasma capsulatum from patients with AIDS who failed fluconazole. J Antimicrob Chemother 2006;56:1235-9.

24. LeMonte AM, Washum KE, Smedema ML, Schnizlein-Bick C, Kohler SM, Wheat LJ. Amphotericin B combined with itraconazole or fluconazole for treatment of histoplasmosis. $J$ Infect Dis 2000;182:545-50.

25. Wheat LJ, Cloud G, Johnson PC, et al. Clearance of fungal burden during treatment of disseminated histoplasmosis with liposomal amphotericin B versus itraconazole. Antimicrob Agents Chemother 2001;45:2354-7.

26. Loeffler J, Stevens DA. Antifungal drug resistance. Clin Infect Dis 2003;36:S31-41.

27. Freifeld A, Proia L, Andes D, et al. Voriconazole use for endemic fungal infections. Antimicrob Agents Chemother 2009;53:1648-51.

28. Kohler S, Wheat LJ, Connolly P, et al. Comparison of the echinocandin caspofungin with amphotericin $B$ for treatment of histoplasmosis following pulmonary challenge in a murine model. Antimicrob Agents Chemother 2000;44:1850-4. 